\title{
ENTRE O VENENO E O REMÉDIO, A LITERATURA: NARRATIVAS DA DOENÇA E DA CURA NA FICÇÃO DE MIA COUTO
}

\author{
BETWEEN POISON AND REMEDY, THE \\ LITERATURE: NARRATIVES OF ILLNESS AND \\ CURE IN THE FICTION OF MIA COUTO
}

\author{
José Welton Ferreira dos Santos Júnior ${ }^{1}$ \\ Rejane Vecchia da Rocha e Silva ${ }^{2}$
}

\section{RESUMO}

Este artigo realiza uma leitura do romance Venenos de Deus, Remédios do Diabo, de Mia Couto, procurando destacar algumas representações do que se refere a temas como doença e cura no universo cultural de Moçambique. Para tanto, propõe-se a leitura da narrativa ficcional de Mia Couto sob as lentes das imbricações com os campos da história, das ciências sociais e de certos pressupostos da medicina social, a fim de verificar a hipótese de que o autor constrói sua crítica à hegemonia do saber ocidental, desvelando cosmovisões alternativas engendradas nas práticas culturais de povos africanos. PALAVRAS-CHAVE: Ciência; doença; Mia Couto.

\section{ABSTRACT}

This article is a review of Mia Couto's novel Venenos de Deus, Remédios do Diabo, highlighting some representations of aspects which refer to themes such as illness and cure in the cultural universe of Mozambique. For this, it is proposed to read the fictional narrative of Mia Couto under the overlapping lenses of history, social sciences and certain assumptions of social medicine, in order to verify the hypothesis that the author builds his criticism of Western knowledge hegemony unveiling alternative worldviews engendered in the cultural practices of African peoples.

KEYWORDS: Science; illness; Mia Couto. 


\section{CIÊNCIA: DA AUTORIDADE À ALTERIDADE}

A ciência não é feita apenas de achados mecânicos, químicos e bioquímicos. É também a mobilização dos recursos e das energias que estão latentes no homem e que, na maior parte dos casos, ainda estão por explorar e conhe-

cer. (Ki-Zerbo, 2006, p. 90)

Mapear o saber científico é percorrer um longo caminho, no qual vozes vão se sobrepondo e envolvendo aspectos sociais, econômicos, históricos, políticos e culturais complexos que concorrem para a construção de pretensas e hegemônicas verdades. Se propusermos um breve recorte temporal partindo de 1860, é possível dizer da ascensão e da confiança da sociedade burguesa diante de suas descobertas científicas. Estabelecendo, sem dúvida, um diálogo com o historiador britânico Eric Hobsbawm (1996), entendemos com ele que os "Homens cultos do período não estavam apenas orgulhosos de suas ciências, mas preparados para subordinar todas as outras formas de atividade intelectual a elas. ” (Hobsbawm, 1996, p. 349).

O historiador, no capítulo "Ciência, religião e ideologia" do livro A era do capital, dedica especial atenção ao avanço do conhecimento da ciência para oferecer um substantivo substrato para a compreensão de que os aspectos da força da estrutura burguesa se manifestam, também, na ascensão e avanço científicos desse período. Observando as imbricações entre os campos da economia e da produção formal de conhecimento, acompanhamos uma leitura atenta que nos leva à percepção histórica das tensões e das contradições a que nos propomos refletir por intermédio do romance de Mia Couto: o saber ocidental (eurocêntrico e hegemônico) versus as cosmovisões alternativas (resultantes de processos históricos diversos no continente africano).

Interessa-nos, inicialmente, em diálogo com as proposições de Hobsbawm (1996), identificar pontos fundamentais para a formação da hegemonia do saber científico no Ocidente, o que levou à constituição de um paradigma central diante da produção de conhecimento, com um espectro ampliado das ciências naturais às ciências humanas e sociais até as rupturas epistemológicas hoje em curso. Ainda com Hobsbawm (1996), afirmaríamos que:

A evolução liga as ciências naturais às ciências humanas ou sociais, embora o último termo seja anacrônico. Porém, a necessidade de uma ciência específica e geral da sociedade (distinta das várias disciplinas relevantes já tratando com assuntos humanos) era pela primeira vez sentida. A British Association for the Promotion of Social Science (1857) tinha o modesto objetivo de aplicar métodos científicos às reformas sociais. (Hobsbawm, 1996, p. 362) 
Nesse sentido, vale ainda destacar a importância do século XVI como um período em que já se manifesta um novo e paradigmático discurso científico ocidental. É naquele período que ocorrem as primeiras revoluções científicas, tendo em Copérnico e em Galileu os pilares de um discurso que formará e conformará o pensamento científico moderno.

Contudo, até o século XIX, o saber científico esteve restrito às ciências naturais e esteve ainda marcado por traços do modelo que caracterizou as experimentações aristotélicas na Antiguidade. É evidente que mudanças fundamentais surgiram com os avanços do século XVI, mas foi o século XIX que assistiu às tentativas de sistematização das ciências. Ainda segundo Hobsbawm (1996):

Diferentemente das ciências naturais, numa sociedade liberal, as ciências sociais não tinham nem mesmo o estímulo do progresso tecnológico. Já que o modelo básico da economia parecia perfeitamente satisfatório, não deixava nenhum grande problema a resolver, tais como o do crescimento, possível colapso econômico ou distribuição de renda. $\mathrm{Na}$ medida em que esses problemas não estivessem resolvidos, as operações automáticas da economia de mercado (sobre as quais as análises então se concentravam) iriam resolvê-los, desde que não estivessem fora de solução humana. De qualquer maneira, as coisas estavam obviamente progredindo e melhorando, uma situação que tornava difícil que as mentes dos economistas se concentrassem em aspectos mais profundos de sua ciência. (Hobsbawm, 1996, p. 364)

A tendência à quantificação foi, dessa forma, um dos grandes fomentos para a consolidação de um discurso científico, no qual o controle absoluto do mundo pelo homem significava atingir medidas inquestionáveis, estabelecendo protocolos de verdade que ainda hoje alicerçam o saber científico. Todavia, os limites dessa tendência quantificadora das ciências logo emergiram, evidenciando desajustes na aplicabilidade do modelo das ciências naturais às ciências humanas, por exemplo. Nesse contexto, o paradigma dominante das ciências foi se consolidando à medida que tentava ultrapassar as limitações que, eventualmente, emergiam e o desestabilizavam, garantindo sua hegemonia no âmbito da linguagem e do discurso comungado pela comunidade científica que operava como legitimadora desse modo de saber.

Assim, os séculos XIX e XX acompanharam o fortalecimento das aspirações globais e totalitárias do saber científico, operando no erigimento de barreiras pretensamente sólidas que desqualificavam quaisquer formas de conhecimento não inseridas no contexto da ciência moderna, no qual imperava a racionalidade cartesiana que hierarquizava o homem em relação ao mundo, colocando-o numa situação privilegiada de domínio da natureza. Nesse sentido, o saber científico hegemônico, para garantir sua supremacia, precisou desprestigiar outras formas de saber, como era previsível. 
Embora os territórios nacionais, de um modo geral, tenham processos históricos específicos do ponto de vista macro e microssistêmico, é possível aproximar, em certa medida, e de forma confluente, o processo de desenvolvimento das ciências e os colonialismos no continente africano a partir do século XIX. Vale observar que, mesmo em países europeus em que se verifica um conhecimento e um convívio bastante antigo com povos não-europeus, os interesses em relação às populações do continente africano só ganham feição de investigação científica no século XIX, período no qual a presença europeia em contextos africanos se organiza densamente, sobretudo depois do projeto imperialista sistematizado na Conferência de Berlim. Diante disso, como afirmam Comaroff e Comaroff (1992), a África se torna uma espécie de laboratório para o desenvolvimento das ciências europeias.

O contato com povos cultural e fenotipicamente diferenciados acaba por se transformar em um contexto marcado pelos ímpetos de sofisticação da ciência, na tendência à classificação e à hierarquização, construindo um caminho assaz produtivo para o desenvolvimento do racismo, além de fomentar os projetos europeus de exploração das populações africanas. Segundo Comaroff e Comaroff (1992), em um estudo antropológico que toma as populações da África do Sul no contexto colonial, a articulação entre as ciências, - com especial destaque para a biomedicina - e o colonialismo não ocorre de forma automática, mas por intermédio de um tipo de processo histórico que registra a penetração dos saberes medicinais trazidos pelos europeus e que repercutiu na construção de uma ideia na qual o corpo negro do africano passa a ser identificado como lócus de doenças e, portanto, suscetível ao controle por parte da medicina europeia.

Da presença dos missionários a uma efetiva participação de médicos, o corpo dos africanos se tornou espaço de intervenção que se inseria num projeto mais amplo da dominação colonial e do controle das populações. Segundo Comaroff e Comaroff (1992):

Com a ascensão do estado colonial, os médicos missionários na África do Sul se viram eclipsados pelos recém-formados órgãos de saúde pública. Na virada deste século, o argumento deles sobre a civilização da África deu lugar a uma preocupação prática com a higiene das populações negras - e com o projeto de domar a força de trabalho "nativa". Aqui, como em outras partes do mundo colonizado, as pessoas eram disciplinadas e as comunidades redistribuídas em nome do saneamento e do controle das doenças (Comaroff; Comaroff, 1992, p. 216, tradução dos autores)

Essa observação sobre o comportamento de alguns cientistas do final do XIX e início do XX é corroborada por Robert Gordon (1998) quando afirma que tal comportamento "possibilitou relacionar a época do imperialismo e a interpretação europeia da sexualidade e a forma como estas intersecções retóricas tornaram clara uma conexão entre antropologia, 
sexologia e imperialismo" (Gordon, 1998, p. 27). É possível notar, portanto, que o desenvolvimento da ciência eurocêntrica esteve vinculado a um imaginário sistêmico e dominante no qual o continente africano aparecia como lugar de testes e experimentações, tornando as investigações biológicas e antropológicas interfaces dos interesses coloniais e da descoberta do outro, o que permitiu a sofisticação e o fortalecimento do quadro retórico da dominação colonial.

Desse modo, tal processo provocou impactos significativamente sérios no âmbito do campo simbólico para a definição da doença e da cura. Em um primeiro momento, é preciso apontar a presença dessas práticas medicinais por meio dos missionários, que se ocupavam de divulgar, salvo alguns casos, a necessidade de um controle sanitário das práticas africanas. Os missionários, nesse contexto, cristalizavam a imagem de salvadores que iriam operar uma missão dupla: limpar e purificar os corpos e as almas africanas. A afirmação de Megan Vaughan (1995), em um estudo sobre a sífilis em Uganda, parece exemplar:

a conexão entre pecado e doença foi uma característica central da ideologia missionária médica. Uma cura eficaz para qualquer problema médico só poderia acontecer por meio de uma verdadeira conversão." (Vaughan, 1995, p. 246, tradução dos autores)

Com o avanço do empreendimento colonial, os missionários cederam lugar (não sem alguma tensão) aos médicos que faziam parte das organizações de saúde dos governos coloniais. Nesse outro contexto, o controle assumiu dimensões de repressão muito mais intensas, e o corpo negro africano se tornou, mais explicitamente, objeto de observação da ciência. Esse período se caracterizou pelo avanço nos estudos da Antropologia Física e pelo interesse nos estudos daquilo que é considerado específico do corpo negro.

A inserção de um corpo médico europeu e especializado em diversos contextos africanos deve ser compreendida e estendida para além da ação imediata na intervenção de cuidados sanitários em relação aos africanos. Precisa ser considerada dentro do quadro dos colonialismos e articulada às estratégias de controle das populações locais. A compreensão dos fenômenos de contato e confronto entre as práticas da medicina ocidental e as práticas de cura locais recebe uma dimensão ainda mais complexa e densa se observados os processos simbólicos nos quais aquele contato ocorreu.

No âmbito das práticas de cura, tornou-se recorrente um cenário de conflitos epistemológicos, culturais, simbólicos e sociais, o que ascendeu o embate entre as novas conjunturas científicas nas quais a ciência ocidental avançou com seu ímpeto hegemônico e as respostas que as populações africanas rapidamente formularam a partir de seus contextos sociais; e, ainda que consideradas práticas menos legítimas sob o ponto de vista hegemônico europeu, as populações africanas atingidas por esse mo- 
vimento dos colonialismos no continente africano não deixaram de produzir e ampliar endogenamente conhecimentos que circulavam em torno das questões de doença, de saúde e de cura.

É nesse sentido que Jean-Paul Bado (1996) analisa os modos de percepção de doenças em regiões do Sudão, salientando o seguinte: "De fato, a interpretação médica da doença em geral e das doenças em particular depende da percepção do mundo em que se vive" (Bado, 1996, p. 15, tradução dos autores). É possível observar, assim, que o autor aponta para um comportamento bastante complexo, dialético e endógeno na construção da percepção da doença e ele irá denominar esse movimento como "medicine empirique-metaphysique”. No entanto, o pesquisador destaca, ainda, o fato de que essas práticas não são estáticas, chamando a atenção para as potenciais confluências, inclusive, entre as práticas medicinais modernas e aquelas comuns às populações africanas que a despeito dos colonialismos acabaram por acontecer. É nessa direção que a oposição declarada ao termo "tradicional" demarca a necessidade de Bado (1996) em salientar que as práticas "empirique-metaphysiques" não se contrapõem aos avanços do modelo científico moderno, pois, segundo o autor, aquele paradigma se define a partir de "ideias recebidas em uma medicina do passado que se perpetua, quer julguemos boa ou ruim hoje." (Bado, 1996, p. 16, tradução dos autores).

O conceito de empirismo, portanto, segundo este autor, trata do diferencial na definição de tais saberes da "medicine empirique-metaphysique". A partir de um dado contexto filosófico e social é que se define o modo pelo qual o empirismo se torna a maneira de aprendizado e a troca de experiências estabelecendo o cerne da aplicação daquela medicina. Definido como um processo de reprodução por imitação, o empirismo, segundo Bado (1996), subordinaria a relevância da razão, organizando estruturalmente saberes que prescindem da reflexão. No limite, o autor estabelece uma espécie de hierarquia que coloca o saber empírico-metafísico dos africanos em um nível menos desenvolvido do que aquele considerado científico. O que está em evidência é o modo como uma noção de ciência encapsulada nos moldes daquilo que hegemonicamente foi definido como ciência se torna a baliza para a interpretação da forma como os africanos mobilizam certos saberes para lidar com a doença.

Acrescente-se ao conceito de empirismo aquilo que o autor lê como metafísica, definindo uma prática medicinal ainda imbricada à religião, salientando, portanto, um nível de desenvolvimento menor do aquele experimentado pela medicina ocidental:

Pode-se dizer que a medicina da maioria das sociedades seguiu um desenvolvimento linear durante os séculos passados, baseado na observação e na experiência, e confinado a uma interpretação religiosa dos fatos. A tradição respeitada tem sido observar e interpretar religiosamente; daí seu caráter metafísico que permeia a definição de causas e tratamen- 
tos de doenças. Diante de outros métodos de cuidado, como os da Europa, a medicina empírico-metafísica tem emprestado, na medida do possível, o que lhe faltava. (Bado, 1996, p. 17, tradução dos autores).

As conclusões a que Bado (1996) chega apontam para a complexidade das práticas de cura e das concepções de doença que norteiam as culturas africanas, marcadas, inclusive, por estratégias de empréstimos produtivas. Não havendo uma nítida separação entre a dimensão corpórea e a dimensão espiritual, o trato com a doença e as práticas de cura se inscrevem num complexo de questões que ultrapassam a taxionomia do saber científico moderno.

\section{NARRATIVAS DA CURA E DA DOENÇA: ESBOÇOS DE UMA CIÊNCIA PARA A VIDA}

No cenário dos colonialismos, os processos de conflitos culturais redimensionavam as formas de percepção da doença e mobilizavam aportes simbólicos que se inseriam em dinâmicas de leituras e interpretação mútuas para universos culturais distintos. Diante disso, ao associar os temas da doença, da cura e da memória aos colonialismos, e mais especificamente ao colonialismo português, buscamos empreender uma leitura de índices simbólicos que compõem microcosmos de um processo histórico que diz respeito não apenas ao continente africano, como também evoca a experiência da alteridade como elemento fundamental para a construção do conhecimento.

Tomamos como representação a narrativa Venenos de Deus, remédios do diabo, de Mia Couto, que, dialogando com os influxos que subjazem as estratégias de dominação colonial em Moçambique, incorpora aspectos da atual conjuntura política e social inscrita pela contemporaneidade, na qual as fronteiras do mundo se veem alargadas e diversas formas de saber vêm questionar a hegemonia cultural dos modelos ocidentais.

Dessa forma, o romance de Mia Couto se volta para elementos pertencentes a cosmovisões alicerçadas em experiências históricas específicas de populações africanas diante de suas formas de intervenção no real, convocando a um exercício hermenêutico crítico que pretende desestabilizar o ímpeto totalitário e hegemônico instituído pela racionalidade científica ocidentalizada e predominantemente eurocêntrica.

Em um de seus conhecidos textos de intervenção, "Que África escreve o escritor africano", encontramos indícios importantes do projeto literário e, talvez, político que parecem alicerçar a produção literária de Mia Couto. No referido texto, o autor traz reflexões que contribuem para acentuar algumas especificidades significativas de sua escritura, na medida em que se distancia de qualquer perspectiva redutora ou totalizante do continente africano, tornando evidente a necessidade de perceber as lógi- 
cas que operam no cotidiano das populações africanas que, mesmo não se opondo completamente à conduta considerada ocidental, visto que o processo histórico de formação daqueles contextos não pode subsumir a presença do colonialismo, movimentam-se em torno de experiências que muitas vezes ensejam dinâmicas culturais complexas que fogem aos padrões interpretativos hegemônicos do Ocidente:

O nosso papel [do escritor africano] é o de criarmos pressupostos de um pensamento mais nosso, para que a avaliação do nosso lugar e do nosso tempo deixe de ser feita a partir de categorias criadas pelos outros. E passarmos a interrogar aquilo que nos parece natural e inquestionável. (Couto, 2005, p. 59-60).

Sendo assim, Mia Couto (2005) oferece-nos um manifesto que procura problematizar algumas questões acerca do significante África e convida-nos a sair do lugar confortável, no qual a África emerge no imaginário social geral a partir de categorias científicas importadas, sobretudo ao longo da ocupação dos opressivos colonialismos no continente. Além disso, problematiza e questiona, em seus textos, os limites do saber ocidental na decodificação de uma linguagem que só pode ser compreendida dentro de um universo cultural ancorado em aspectos latentes da ancestralidade que contribuem para a organização da vida social e material de diversos povos. As dinâmicas sociais, então, se fundamentam em uma experiência na qual o coletivo se traduz no indivíduo e vice-versa, processo no qual a natureza assume um papel contumaz.

Ainda nas reflexões de Mia Couto (2005), pode-se verificar uma preocupação que vem se desdobrando em parte significativa de sua produção literária: localizar modos de vida de africanos em contextos em que os pressupostos da chamada modernidade já se instauraram. Tal perspectiva acaba por levantar questões que inserem as dinâmicas africanas em um cenário mais amplo no qual os colonialismos operaram como zonas de contato/conflito, redefinindo a história de populações africanas de forma quase - irreversível.

Dessa maneira, as inquietações de Mia Couto se manifestam estrategicamente em sua escrita ficcional ao articular referenciais de práticas ancestrais que configuram sistematicamente o cotidiano das pessoas naqueles contextos aos processos políticos e sociais comuns à contemporaneidade dos territórios africanos, lidando com dinâmicas geopolíticas complexas nas esferas interna e externa. Considerando algumas questões conceituais concernentes às historicidades do continente, Couto (2005) reivindica a complexidade de um sistema de trocas: "A oposição entre o tradicional - visto como o lado puro e não contaminado da cultura africana - e o moderno é uma falsa contradição. Porque o imaginário rural é também produto de trocas entre mundos culturais diferentes". (Couto, 2005, p. 61). 
Portanto, é possível afirmar que a textualidade de Couto procura mobilizar uma série de tensões que o colocam, inexoravelmente, assim como tantos africanos que viveram a experiência do domínio colonial, em um contexto no qual planos culturais diversos conformam histórias complexas, nas quais dicotomias estanques perdem de vista todo um complexo, distinto e multifacetado universo cultural que se deslinda em narrativas entrecortadas por temporalidades e visões de mundo marcadas por contradições, descontinuidades, mas também projeções, esperanças e desejos.

Dessa maneira, as memórias do colonialismo português despontam no processo histórico como uma experiência do passado que ainda opera tanto no âmbito concreto como no simbólico das sociedades que tiveram seus territórios ocupados. Todavia, tais memórias acarretam, também, toda uma trajetória de luta na qual os vínculos telúricos eclodem anunciando a estreita relação dos sujeitos com os territórios africanos, materializada na construção da soberania e na emergência de projetos de estados-nação. E, nesse sentido, vale destacar o significativo contingente das populações rurais que desempenharam papel fundamental na luta de libertação e na ruptura com a exploração colonialista da terra também em Moçambique.

Na obra de Mia Couto, transitam, portanto, personagens imersos nesse cenário tensionado. A busca por conhecimento ampliado, diverso e por sentidos que mobilizem a atenção para o ser e estar no mundo assume contornos narrativos e lança nas páginas dos romances algumas representações de sujeitos que se movimentam anonimamente, contemplando e dinamizando práticas culturais que operam por meio de códigos endógenos complexos. A leitura desse universo só se torna possível quando o leitor se mobiliza para um tipo de experiência cultural em que as explicações pretensamente racionais não significam o único método de compreensão da realidade.

Nesse sentido, Venenos de Deus, remédios do diabo é um romance em que o projeto do escritor mais uma vez é posto em movimento. $\mathrm{O}$ romance, por meio de uma instigante narrativa, aponta para um conflito entre dois mundos, produzindo uma imersão pelos signos e pelos saberes acerca da cura, da doença, dos remédios e os sentidos que eles mobilizam no contexto moçambicano após o período colonial.

A trama focaliza a experiência de um médico português, Sidónio Rosa, que segue para a Vila Cacimba, uma vila localizada em algum ponto do continente africano (como a define o próprio narrador) onde se desenrola a ação da narrativa, em busca de Deolinda, jovem moça por quem se apaixonara em Lisboa. Remontando a trajetória histórica dos portugueses que seguiram rumo à África, a estória da personagem cria deslocamentos em relação ao discurso hegemônico do colonialista português. Os saberes que organizam o mundo conceitual de Sidónio Rosa se mostrarão muito limitados diante dos signos e dos sentidos que compõem os universos cul- 
turais dos africanos de Vila Cacimba. Será, portanto, em meio a um labiríntico percurso, que Sidónio Rosa escreverá uma outra história do contato do europeu com os africanos, na qual o médico se lança como hermeneuta em um contexto que evidencia uma potência significante para além dos discursos que enunciam a África plenamente conhecida:

Sidónio Rosa apenas conhece um caminho no labirinto de atalhos da Vila Cacimba: a ruela que liga a pensão ao posto de saúde e à casa dos Sozinhos. E é esta mesma rua de areia que ele, neste momento, percorre como se fosse um campo minado. Salta à vista: é um europeu nas profundezas de África. O passo é calculado, quase em bicos dos pés, o olhar cauteloso garimpeirando o chão. Ele não confia, a sua sombra não é comandada por ele. (Couto, 2008, p. 75).

O périplo materializa, portanto, o desconhecido. A pretensão conquistadora que alimentou o sonho do colonialismo abre espaço à hesitação, num território marcado por mistérios, que, para além de uma metafísica, instaura um texto que solicita leituras atentas às camadas e camadas de estórias que se sobrepõem, num tecido instável e repleto de sentidos moventes.

Atravessada por metáforas da doença e da cura, a narrativa se desenrola colocando em seu cerne a aproximação entre o médico, Sidónio, e seu paciente, Bartolomeu Sozinho, pai de Deolinda. Da experiência da doença, emerge o apelo do velho moçambicano que convoca Sidónio Rosa a produzir leituras acerca da doença naquele contexto. Dessa forma, o exercício diagnóstico e terapêutico é marcado por contradições, por relações de rejeição e de adesão, como se observa nos seguintes fragmentos das falas de Bartolomeu: "E mais, Doutor: acho que o senhor não tem nada a fazer aqui. Eu vivo tão sozinho que nem doença tenho para me acompanhar" (Couto, 2008, p. 17), ou ainda, "Me receite um remédio para eu desmaiar" (Couto, 2008, p. 113). Isso remete à suspeição com que as populações africanas encaravam as práticas medicinais ocidentais, com as quais negociaram ativamente de diversas formas segundo seus próprios padrões culturais.

Os fios da narrativa que enredam o português à vida dos Sozinhos, Bartolomeu e Munda, pais de Deolinda, engendram a complexa dinâmica que coloca os sentidos da doença e da cura em permanente movimento, na qual os saberes locais são articulados àqueles plasmados pela biomedicina, como sintetiza Munda ao se dirigir a Sidónio: “O senhor estudou doenças. Eu aprendi foi na doença” (Couto, 2008, p. 29). A síntese aponta para a natureza distinta e suplementar dos saberes ali encenados.

Em meio às tensões epistemológicas e culturais que aquele contato promove, há a materialização da experiência das confrontações que o continente africano historicamente vem experimentando, na qual as práticas locais se veem diante de dinâmicas advindas da relação opressiva com o colonizador. Haveria, portanto, uma espécie de associação complexa, dialética e opressiva entre as práticas de cura dos africanos e aquelas da 
biomedicina. Tais processos revelam justamente os graus da confrontação histórica resultante dos colonialismos que acabaram por gerar articulações que ultrapassam dicotomias reducionistas e leituras equivocadas da história. Sobre a questão, Jean-Paul Bado (1996) afirma que:

Deve-se admitir que a medicina da África pré-colonial e colonizada foi enriquecida por novas contribuições da Europa Ocidental. Na própria África, houve troca de conhecimento, até transferências de "fetiches" e cultos. Estes elementos indicam que o termo medicina "tradicional" tem uma conotação de rigidez. Parece estacionário, até bloqueado em seu funcionamento, porque seria regulado por um conhecimento fechado e estático que se oporia ao conhecimento aberto e dinâmico que conduz à cultura científica." (Bado, 1996, p.16, tradução dos autores).

Na medida em que a presença do médico português se apresenta como um dado fundamental no restabelecimento da comunidade diante de um quadro epidêmico, a constatação das limitações do seu saber científico é a todo momento ratificada, o que evidencia os limites das percepções da doença apenas por causas objetivas:

A epidemia que atingiu Cacimba está-se alastrando. Mais e mais pessoas são atacadas de febres, delírios e convulsões. $\mathrm{O}$ português recém-chegado é o único médico e não está dando conta da situação. Quem sabe a enfermidade é de outra ordem que escapa às ciências? (Couto, 2008, p. 37)

Susan Sontag (2007), ao analisar os processos simbólicos em torno da tuberculose e do câncer, assevera que, para além das causas fisiológicas, a doença mobiliza significados, a partir dos quais são construídos sentidos tanto para a doença, quanto para a sua inserção social. A subjetividade, portanto, atravessa o modo objetivo como a ciência encara a doença que se instala no sujeito e lhe confere nova condição social.

No romance de Couto (2008), essa relação é dinamizada pelo léxico do texto, que se arvora na nomeação de doenças como malária, diabetes, mas também dilata os sentidos da doença a partir de escolhas lexicais alicerçadas na percepção holística das culturas africanas: "Cure-me de sonhar, Doutor” (Couto, 2008, p.16), diz Bartolomeu ao médico, e continua: "Um sonhadeiro anda por aí, por lonjuras fazendo o quê e com quem... Não haverá um remédio que me anule o sonho?" (Couto, 2008, p. 17). O sonho, como um dado que define a interação de Bartolomeu com a Vila, se apresenta como elemento por meio do qual a doença alegoricamente aponta para a persistência das memórias dos tempos coloniais. Ao permanecer no navio dos tempos da Companhia Colonial de Navegação, no qual havia atuado como ajudante de mecânico, o velho adoece ao reviver contidamente os atos de embarcar e de desembarcar e, nesse movimento, se desvincula da vivência na Vila Cacimba, de modo que os sintomas da doença escamoteiam verdades mais profundas associadas ao próprio trau- 
ma da colonização: "Nos reais tempos nocturnos, o mecânico é atacado por insónias, acaloradas friagens, frígidas febres" (Couto, 2008, p. 24) e cuja despersonalização de Bartolomeu é um forte indício: "De tanto ir e vir, ele já trocava partida por destino. De tanto viver no mar, ele já perdera pátria em terra. " (Couto, 2008, p. 27).

Seria um equívoco imaginar que sociedades africanas lidam com práticas de cura e concebem a doença de maneira estanque, segundo os paradigmas ditos "tradicionais". As dinâmicas sociais e discursivas que operam no âmbito da saúde devem ser entendidas como parte do processo histórico que redefiniu os povos habitantes do continente africano a partir dos colonialismos, interferindo nas narrativas pessoais e coletivas que engendram e oferecem sentido ao mundo em volta.

O médico Sidónio Rosa, então, torna-se partícipe desses processos, encarnando a figura do europeu que, legitimado pelo saber científico, penetra o universo da doença e da cura na África: "Ele é médico, europeu, senhor das poderosas sabedorias" (Couto, 2008, p. 117), e se sente obrigado a decodificar um mundo simbólico para o qual as pretensas objetividades da ciência são apenas uma pequena dimensão da verdade.

A experiência de Sidónio Rosa ao se fazer crítica desvela uma paisagem social que desafiou os instrumentos dos saberes científicos, tendo produzido uma série de hierarquias que revelam o desconhecimento vinculado ao projeto de dominação marcado por estereótipos e por uma visão redutora:

Aos poucos, a estranheza dá lugar ao medo. Ali começa um continente que Sidónio Rosa desconhecia. Apercebe-se quanto a sua África era reduzida: uma praça, uma rua, duas ou três casas de cimento [...] No fundo, o português não era uma pessoa. Ele era uma raça que caminhava, solitária, nos atalhos de uma vila africana. (Couto, 2008, p. 116-117).

A personagem de Sidónio Rosa recupera simbolicamente, em certa medida, o perfil de alguns cientistas que, diante do contexto colonial, se lançaram sobre a África, identificando-a como uma estufa, como apontam os Comaroff (1992), na qual se daria a observação de fenômenos fisiológicos e bioquímicos importantes para o avanço da ciência. O que muitos desses cientistas não conseguiram ou não quiseram perceber é que essas pessoas constituíam saberes que buscavam explicar a partir de experiências cotidianas, entre elas, aquelas concernentes à doença. Por vezes, esses saberes constituíam narrativas que se opunham àquilo que os médicos e seus conhecimentos julgavam acertados.

A fuga de Bartolomeu Sozinho do hospital evidencia a ruptura com o controle do corpo de africanos e com todo um quadro de conhecimento representado pela dominação epistêmica da biomedicina e suas terapias. Mais uma vez, as leituras são confrontadas: onde o médico via indício de cura e de altruísmo; Bartolomeu identificava a aproximação da doença e as garras da exploração: 
Não saiu, fugiu. Tinham-lhe ligado a veia a um soro, dada a sua debilidade. Os alimentos desciam-lhe contra a corrente sanguínea. Para Bartolomeu era o inverso: ele é que estava alimentando o hospital, com os fluidos que lhe extraiam. Esse sangue roubado circulava agora pelo edifício, escorria pelos fundos e se espelhava no vermelhão dos poentes. "O hospital é um lugar doente", reclama o velho. Ao escapar-se daquele antro ele regressava para os seus antigos recantos. "Eu a e casa sofremos de uma mesma doença: saudades" (Couto, 2008, p. 12).

Por outro lado, mesmo no contexto dos colonialismos, alguns cientistas conseguiram driblar os preconceitos mais destacados e tiveram sucesso no mapeamento das práticas de cura que organizavam contextos africanos. Nessa perspectiva, ganham relevância os estudos de Junod (1996), missionário, entomólogo, que foi responsável por uma densa etnografia dos tsonga em Moçambique, no século XIX.

Na obra de Junod (1996), destacam-se as observações acerca da constituição de sistemas de cura e de cuidado com a doença, salientando articulações entre práticas objetivas, que lidavam com o uso de ervas, e práticas rituais, das quais a magia e a religião seriam parte constitutiva. Magia, arte médica e religião assumem, portanto, na análise de Junod (1996), o ponto fundamental para o entendimento das doenças e das curas no contexto dos tsonga; o que fica também evidente é o fato de que, nesse ponto, as práticas de cura africanas se distanciam do modelo outorgado pela ciência moderna, no qual o processo de legitimação esteve alicerçado na obsessão pela objetividade, provavelmente condicionada pelos métodos quantificáveis advindos das ciências naturais e aplicáveis a todo objeto. Sobre a prática dos tsonga, Junod (1996) afirma que:

A confusão destes três domínios [magia, ciência e religião] no espírito dos indígenas explica, também, o carácter complexo dos indivíduos que praticam a arte médica ou mágica. O médico indígena, n’anga, está longe de ser simplesmente um homem de ciência; tem, também, mais ou menos, alguma coisa do feiticeiro e também invoca os antepassados que lhe transmitiram os seus feitiços. O curandeiro, mungoma, é, por vezes, uma espécie de padre-quando, por exemplo, se põe a exorcismar os espíritos dos possessos. O adivinho, wavula, cuja arte se baseia inteiramente em concepções mágicas, reza, ocasionalmente, aos seus antepassados deuses para que o auxiliem na consulta aos ossículos que recebeu deles. (Junod, 1996, p. 388)

O imbricamento entre os campos da religião e da ciência há muito tem sido foco de observações nos contextos africanos. As investidas dos missionários no século XIX, como é o caso de Junod (1996), mapeavam essa relação como um déficit frente aos ímpetos que norteavam as ambições científicas daquele período. 
Confundidas com superstições, atraso e tradicionalismo, as respostas que os africanos lançavam ao contexto da doença, intervindo com práticas pouco ortodoxas nas quais os limites entre preces e rituais a ancestrais se confundiam com o uso de plantas com propriedades bioquímicas, eram objeto da curiosidade antropológica, mas hierarquicamente subordinada à pretensão da ciência "verdadeira".

Terence Ranger (1995), em "Plagues of beasts and man: prophetic reponse to epidemic in eastern and southern Africa", apresenta um complexo quadro no qual a religião assumiu status privilegiado na intervenção diante de casos de epidemia no continente africano. $\mathrm{O}$ autor aponta para o fato de como três sistemas religiosos, que ele classifica como Islã, Cristianismo e Religiões Africanas, contribuíram para o controle de doenças epidêmicas. O mais notável de todo esse processo é que a intervenção no nível da saúde pública, argumenta Ranger (1995), esteve articulada ao surgimento de figuras proféticas que conseguiram mobilizar a população, obviamente lançando mão de um expediente complexo que incluía narrativas míticas e cuidados espirituais. Tais considerações permitem verificar o quão complexas e duradoras foram e são as relações entre ciência e religião em diversos contextos do continente africano.

Partindo desse pressuposto, a narrativa de Mia Couto, embora só aluda efetivamente à prática medicinal europeia e não faça alusão à presença de curandeiros, por exemplo, evidencia, a partir das narrativas das personagens, referências aos saberes locais que circulam e que interpõem ao médico português obstáculos na compreensão do quadro de doença e as intervenções necessárias à cura. Vê-se, pois, nesse exemplo, a penetração do mundo religioso, que, é preciso salientar, não tem exatamente o mesmo significado que aquele atribuído pelos ocidentais, mas trata-se de uma relação intensa e cotidiana que visa ao equilíbrio do plano imaterial, onde habitam os ancestrais e os espíritos, com o plano material, onde cotidianamente a vida segue, nos grandes centros ou na roça.

No âmbito da doença, quando as respostas parecem ainda mais urgentes, a relação com o intangível se torna ainda mais marcada e as práticas medicinais se misturam aos rituais que buscam reestabelecer o ciclo natural da vida, execrando a desestabilização trazida pela doença. Isso pode ser constatado no diálogo entre o médico e a autoridade local:

- Essa doença misteriosa que se espalhou por aqui: o senhor já tomou as providências?

- Eu acho que se trata de meningite.

- É uma doença, digamos, que encomendável?

- Não entendo.

- Pergunto se alguém...digamos, um inimigo político, poderia ter encomendado.

- É uma doença que ocorre sobretudo nas pessoas que se concentram em recintos fechados. É por isso que os soldados são os mais atingidos... 
- As pessoas pensam que é mau olhado

- As pessoas não pensam...

Suacelência adivinha a retórica do europeu. Ergue o braço autoritário, mas abre mão à paciência para que o estrangeiro entenda. (Couto, 2008, p. 68).

A família Sozinho, esfacelada pelo colonialismo, pela guerra, pela doença, protagoniza a ruptura desses laços. A saída misteriosa de Deolinda é o símbolo da desarticulação da família, desencadeando o contexto da doença. Dessa maneira, são recorrentes as interrogações de Bartolomeu Sozinho sobre sua doença. As respostas às perguntas retóricas do velho colocam a ausência da filha no cerne do problema. A questão torna-se ainda mais intensa ao final do romance, quando é descoberto que Deolinda está morta, segundo indícios da narrativa, acometida por alguma doença sexual. Essa morte, contudo, não é aceita, e a presença da moça continua subjacente à estrutura da família. No limite, pode-se falar simbolicamente da ruptura que a morte não-natural insere, rompendo o ciclo da vida na casa dos Sozinho.

Muito do que é apontado por Junod (1996) acerca das concepções da doença se encontra representado na fala das personagens africanas na narrativa de Mia Couto, o que acaba se constituindo como mais um elemento a ser decodificado pelo médico. Os signos veiculados pela doença extrapolam a dimensão pessoal do doente e se ramificam no corpo social. Nota-se, portanto, que a doença assume um papel relevante no ordenamento das relações sociais, criando aproximações e distanciamentos entre os sujeitos e reiterando o sentido de coletividade, tendo em vista que a cura perpassa pela busca do equilíbrio em todas as esferas da vida.

Como elemento externo, a doença é encarada como algo que foi introduzido, segundo Junod (1996), tomando como exemplo os tsonga: "há três grandes causas de doença: os espíritos dos deuses, os deitadores de sortes e os makhumu, ou seja, a poluição da morte e contato com as pessoas impuras" (Junod, 1996, p. 408). Um fragmento do romance alude a temas semelhantes, como pode ser verificado a seguir:

Desde há muito que Munda ganhava a vida lavando roupa para o pequeno hospital da Vila. Mas agora, que eclodira a epidemia, o marido se opõe a que a roupa contaminada dos tresandarilhos entre no quintal de sua casa. Não importava que esses lençóis venham já desinfectados. (Couto, 2008, p. 30)

Nesse sentido, toda e qualquer doença compreende uma leitura que considera as causas fisiológicas, mas as explica em diálogo com o mundo intangível. A relação de transgressão com os ancestrais e a feitiçaria podem emergir como causas da doença e mobilizam narrativas que compõem o universo cultural de africanos, definindo uma relação complexa diante da qual a busca da cura se amplia da dimensão biológica/fisiológica para a dimensão espiritual. Essa perspectiva pode ser verificada no seguinte trecho da narrativa: 
A mais recente obra de feitiçaria de Munda poderia ser, por exemplo, a praga que recaiu sobre os soldados enlouquecidos. Mais do que outros exércitos, esses homens haviam, durante a guerra civil, desafiado os poderes da natureza divina. Os tresandarilhos estavam pagando o preço dessa transgressão. Tudo por causa dos secretos poderes de Munda. (Couto, 2008, p. 59).

Portanto, como se nota, a epidemia de soldados enlouquecidos, os tresandarilhos, ganha explicação em causas sobrenaturais, que se vinculam à concreta situação da guerra, uma possível metáfora do sem-sentido, do descabido, do irregular, que tanto a guerra como a doença promovem na vida das pessoas.

Além disso, a doença situa o sujeito num estágio de transformação que, ao lançá-lo no universo dos doentes, impede uma experiência social integrada à comunidade. A metamorfose é diluída em metáfora e ganha vazão no plano mítico que compõe a narrativa: "Era o que dizia o seu Bartolomeu: que era maleita de família, também ele estava a caminho de se largatear. A única coisa, porém, que vai rastejando, rente às poeiras, é a sua pobre alma" (Couto, 2008, p. 13). O ato de transformar-se em lagarto sugere, provavelmente, a desumanização do sujeito que passa para o mundo dos doentes após ser acometido pela doença. Aspectos metonímicos do lagarto se projetam sobre o doente e rebaixam sua condição ao nível rastejante.

A partir de tal perspectiva, a narrativa de Mia Couto oferece indícios nos quais a metáfora da doença, que parece não ser definida por uma denominação objetiva, desvela traços da experiência social. As referências à doença como um estágio que foge à dimensão normal e que, portanto, carece de intervenção dimensionam uma memória traumática que lança seus tentáculos sobre a desagregação social, representada pelo esfacelamento da família, num nível micro, mas também da nação.

A doença assume um papel balizador nas relações sociais, delineando a percepção do contexto social a partir do equilíbrio necessário entre o mundo tangível e o mundo intangível, como já observara Junod (1996) anteriormente. Diante disso, processos de intervenção e tabus são orientados para o doente, como acontece com Bartolomeu Sozinho, que, tendo a doença como companhia, tem acesso ao mundo social pela janela:

Sidónio sabe da rotina de Bartolomeu: domingo é dia janela. A meio da manhã, ele se desamarra do reumatismo, ergue-se arrastoso e se encosta na luz, a contemplar a rua. Meio oculto entre os cortinados, não vê muito, quase não escuta. Melhor assim: os sons desfocados já não o convocam. Apesar de tudo, vai acenando. De que vale estar à janela se não é pra dizer adeus? (Couto, 2008, p. 18).

Assim, sentidos pretensamente banidos do mundo da ciência eclodem no romance como uma percepção do quadro da doença que redi- 
mensiona a relação do indivíduo com seu meio. A cura, por sua vez, emerge como resposta à desestabilização e ao desajuste provocados pela doença, inscrevendo um esforço para o retorno ao equilíbrio, o que não se concretiza no romance, tendo em vista que a presença da doença é resultado da ausência de Deolinda:

[...] o destino nunca protegeu a bela Deolinda. Já muito doente, ela veio ter com Suacelência, e pediu que a levasse ao Zimbabwe para consultar com curandeiro. Voltou ainda pior. Nem sequer completou a viagem de regresso à Vila Cacimba [...] O corpo perdera toda substância e os ossos tinham emagrecido tanto que, após o desfecho, não havia mais nada para enterrar (Couto, 2008, p. 174).

Venenos de Deus, remédios do diabo, na produção literária de Mia Couto, parece revelar uma tentativa de romper silenciamentos ao transformar a narrativa ficcional no espaço ideal para que as personagens transitem e possam conduzir o leitor por realidades diversas do continente africano com suas questões de ontem e de hoje. Diante disso, emergem referências de um continente que lida com as memórias dos colonialismos, mas que refuta as investidas de uma colonização do pensamento, como é perceptível também em outros textos do autor, nos quais são problematizados o preconceito e a ignorância.

O mundo da Vila Cacimba permanece incurável, porque está marcado pela desordem instaurada pela doença. No entanto, a narrativa não deixa de mostrar que, segundo a lição das personagens locais, há um ciclo ininterrupto entre a morte e a vida, entre o passado e o futuro, como diz a personagem de Couto (2008, p. 188): “- Eu vim semear estas flores. Tirei-as do cemitério e vou semeá-las por aí, vou semeá-las em toda a Vila Cacimba". Sob a marca das incertezas, o texto de Mia Couto desestabiliza as pretensas verdades do saber científico e defende saberes sensíveis a partir dos quais a literatura pode perpetuar a vida.

\section{REFERÊNCIAS BIBLIOGRÁFICAS}

BADO, Jean Paul. Medicine colonial et grands endemies en Afrique. Paris: Karthala. 1996

COMAROFF, John; COMAROFF, Jean. Ethnography and the Historical Imagination. Boulder: West View Press, 1992.

COUTO, Mia. Pensatempos: textos de opinião. Lisboa: Caminho, 2005.

COUTO, Mia. Venenos de Deus, remédios do diabo: as incuráveis vidas da Vila Cacimba. São Paulo: Companhia das Letras, 2008.

GORDON, Robert. "The rise of the Bushman penis: Germans, genitalia and genocide". African Studies, 57, 1, p. 27-54, 1998.

HOBSBAWN, Eric. A era do capital: 1848-1875. Rido de Janeiro: Paz e Terra, 1996. 
JUNOD, Henri. Usos e costumes dos Bantu. Maputo: Arquivo Histórico de Moçambique, 1996.

KI-ZERBO, Joseph. Para quando África?: entrevista com René Holenstein. Trad Carlos Aboim de Brito. Rio de Janeiro: Pallas, 2006.

RANGER, Terence. "Plagues of beasts and men; prophetic responses to epidemic in eastern and southern Africa". In: RANGER, Terence e SLACK Paul (Eds.). Epidemics and ideas: essays on the historical perception of pestilence. Cambridge: CUP, p. 241-268, 1995.

SONTAG, Susan. Doença como metáfora, AIDS e suas metáforas. Trad Rubens Figueiredo e Paulo Henrique Britto. São Paulo: Companhia das Letras, 2007.

VAUGHAN, Megan. "Syphilis in colonial East and Central Africa: the social construction of an epidemic". In: RANGER, Terence e SLACK Paul (Eds.). Epidemics and ideas: essays on the historical perception of pestilence. Cambridge: CUP, p. 269- 302, 1995.

Recebido para publicação em 30/05/2018

Aprovado em 14/08/2018

\section{NOTAS}

1 Professor da Universidade do Estado da Bahia. Mestre em Estudos Étnicos e Africanos (UFBA) e, atualmente, é doutorando no Programa de Pós-graduação em Estudos Comparados de Literaturas de Língua Portuguesa (USP).

2 Professora de Literaturas Africanas de Língua Portuguesa e do Programa de Pós-graduação em Estudos Comparados de Literaturas de Língua Portuguesa, na Universidade de São Paulo. Doutora em Estudos Comparados de Literaturas de Língua Portuguesa (USP). 